\title{
CONTRA A SÍNDROME DO "QUANTO PIOR, MELHOR"
}

\section{Marcos Gustavo Richter}

Este é um ensaio em estilo livre. Foi escrito como resposta e possível terapêutica aos sintomas de uma perigosa síndrome: a síndrome do "Quanto pior, melhor", infelizmente ainda pandêmica no nosso sistema escolar formal.

Você, leitor(a), seria capaz de imaginar alguém defendendo solenemente a idéia de que, no ensino médio, a função do professor de português não é levar o aluno a ler e escrever, e sim decorar regras de gramática para "passar" em concursos ou vestibulares? E de imaginar quem proclame que ao professor só compete dar suas aulas e ficar no âmbito "educacional", deixando de lado o político - ou seja, que educação é uma coisa e política é outra?

Pode parar de imaginar, caro(a) leitor(a). Pois isso não é mera imaginação - bom se fosse! - é pura realidade. Sem dúvida uma parte dela, dado que - menos mal! uma fatia considerável dos professores de língua materna já dispõe de consciência crítica e profissionalismo para reconhecer o estrago individual e social representado, neste país, pelas manobras "pedagógicas" que favorecem o analfabetismo funcional disfarçado. Estrago, por sinal, nada fácil de reverter: o des-ensino, a longo prazo, deixa seqüelas na clientela que se senta, iludida e assiduamente, nos bancos de bom número de escolas, para, já adolescente, chegar ao ponto de escrever o próprio nome integralmente em letras minúsculas e escrever "textos" sem delimitar sentenças com inicial maiúscula e ponto final (!) - entre outras coisas mais, também gravíssimas.

Ah, e notem bem: esses problemas todos, ressalte-se, após literalmente vários anos de professores(as) "dando gramática". Mas, "dando" o quê? Se algo é dado a alguém, então esse alguém... tem a posse do que lhe foi dado, não é tão óbvio?! Mas o que exatamente os alunos "têm" do que Ihes foi..."dado"?!

Já viram esse ditado: "O pior cego é aquele que não quer ver" ?

Em outro artigo desta edição da Linguagens \& Cidadania, outro docente escreve sobre o problema da (falsa) dicotomia ensino-política. Aqui, me ocuparei especificamente da questão do ensino da língua materna. Sugiro, portanto, que o(a) caro(a) amigo(a) leia ambos. De minha parte, as reflexões se iniciam com o mesmo "gancho", isto é, a partir de um horizonte político, no sentido amplo do termo.

Para ajudar a "pegar no tranco", convido o(a) leitor(a) a se perguntar: se é verdade que hoje subsistem formas erradas e perigosas de "ensinar" (?!) português nas escolas brasileiras - e isso facilmente se vê pela incapacidade quase total de muitos alunos para a leitura e escrita apesar da escolarização então por que ainda há a defesa - estranhamente intransigente, lembrando/constituindo sintomas obsessivos - dessas formas arcaicas de ensino 
por professores(as), coordenações de curso, direções de escola e, de modo implícito, por alguns dos segmentos editoriais ligados ao livro escolar?

Não vou de forma alguma escamotear a complexidade dessa resposta, nem mesmo alegar que se possa esgotar a discussão. Mas gostaria de lembrar, de início, que o indivíduo-docente - contrariamente à etimologia da palavra "indivíduo" - se desdobra em pelo menos dois "eus": um eu-profissional e um eu-pessoa. Ambos estão implicados no fazer pedagógico, de forma que, se o eu-profissional age de determinada maneira, em grande parte o eu-pessoa se acha implicado nisso como um cúmplice. E mais: dado que a relação indivíduo-sociedade é antes de interdependência que de oposição (o eu e o outro são inseparáveis; são duas faces da mesma moeda), analisando-se o caráter social do homem moderno e suas raízes, ou seja, os processos político-econômicos que o originaram, tem-se a justificativa filogenética para as contradições aparentemente espantosas que permeiam o campo educacional não só no Brasil, mas em todo o mundo contemporâneo.

Pois bem. Ninguém ignora que o homem moderno cresce e se desenvolve sob a égide da "livre iniciativa". Liberto dos grilhões do sistema feudal, que fixava em definitivo os destinos de cada indivíduo em função das circunstâncias que o envolviam, o caráter do homem passa a ser determinado pela ideologia da Reforma, num primeiro momento, e logo em seguida pelo sistema de produção capitalista, ambos inextrincavelmente ligados. Sucintamente falando, o homem emerge como indivíduo, autônomo, isolado, responsável por si próprio. O que exatamente isso significa, e traz?

Façamos uma distinção entre "liberdade de" e "liberdade para". O primeiro tipo de liberdade é de natureza negativa, significando ruptura da sujeição a forças que objetificam o homem e obstaculizam seu desenvolvimento como ser responsável e solidário. O segundo é de natureza positiva, consistindo na efetivação das forças que contribuem para a humanização plena do indivíduo: crescimento individual, domínio da natureza, solidariedade e produtividade. A proposta da Reforma consistiu em propor uma "solução" para as angústias que assaltavam o homem do final da Idade Média (cerca do século XV) em decorrência da destruição da ordem subjacente ao sistema social medieval. Nesta, o indivíduo se achava inscrito num lugar fixo das relações econômicas vigentes. Não dispunha de espaço para autodeterminar-se, mas em contrapartida seu grupo lhe fornecia o necessário suporte econômico, cultural e psicológico para estar ajustado à vida.

Com o advento do capitalismo (então mercantil) emergente, o sistema de referências do indivíduo desmorona: passa a faltar-lhe o "chão onde pisar". O homem é deixado só; tudo agora dependerá de seu próprio esforço, e nisso ele se encontra desamparado. Por quê? Entre outros fatores, merece menção a súbita irrupção da incerteza do mercado - incerteza do lado da oferta, incerteza do lado da procura. O mercado medieval era pequeno e facilmente entendido - e, portanto, facilmente previsível. O que é preciso, se sabe bem; o que é disponível (ou ao menos obtenível), também se sabe bem. Ora, com a ampliação do mercado, não mais bastava produzir bens decididamente úteis; além disso e apesar disso, as leis do novo mercado poderiam sem maiores explicações afetar o preço e até a 
possibilidade mesma de venda e, conseqüentemente, de sobrevivência no sistema econômico.

capital emerge como uma força suprapessoal capaz de determinar o destino econômico de cada indivíduo - agora inseguro, isolado e ansioso - conforme suas próprias leis. Trocando-se "capital" por "Deus", obtém-se a síntese da doutrina calvinista da predestinação: o indivíduo deve esforçar-se para ser bom; mas, sendo bom ou não, seu destino está selado de antemão, e quanto a isso, nada pode fazer, exceto sujeitar-se, humilhar-se ao reconhecer sua insignificância e sua plena dependência a um poder externo, que não tem moral nem compaixão.

Resultado: "liberto de" uma ordem econômica que anulava sua individualidade, o homem não pôde fazer uso da "liberdade para" (assumir a responsabilidade pela adequação de seus pensamentos, palavras e atos). Renunciou à liberdade, alienando-a a um poder ferozmente arbitrário (que preside à desigualdade entre os homens!): o Capital, o Estado, Deus, um Ditador, ou mesmo um "algo" que se responsabiliza pelo que esse indivíduo fizer, em troca da cega e obsessiva submissão à "lei", às normas, ao ritual.

Agora, passando à contemporaneidade: imaginem que esse "algo" seja a Instituição Escolar. Já perceberam a analogia - a "mais do que mera coincidência"?

O professor sabe, ou intui, que o sistema vigente esvazia toda a sua auto-estima, toda a significância do que possa tentar fazer pela educação. Sua competência se converte em incompetência; sua formação, em erudição vazia; sua autoridade, em pantomima risível. Para o sistema e seus prepostos, o docente é um mero realizador de rituais vazios, que aliena a responsabilidade pela eficácia do que faz e pelos destinos de seus educandos ao poder feroz desse sistema, a fim de "predestinar" os alunos arbitrariamente desiguais à vida (econômica) eterna ou ao fogo (da exclusão) eterno.

Aproveitando o "gancho" da linguagem da Reforma: como o apóstolo Paulo declara em suas cartas, a Lei só existe para mostrar que deve ser - mas nunca consegue ser - cumprida, dada a impotência, insignificância e impossibilidade de autodeterminação do indivíduo (leia-se agora: para "Lei", Metodologia Tradicional de Ensino; para "indivíduo", docente - e está completa a equação).

Com efeito, nunca se exigiu furiosamente tanto do professor como hoje, e se esperou dele tão pouco! As mudanças no perfil do profissional da Educação mostram bem isso. Ele precisa fazer face à multiplicação das responsabilidades que não é acompanhada, ressaltemos, de mudanças em sua formação: deve acumular, como que miraculosamente, no mesmo espaço físico e dentro da mesma carga horária (ou maior), além da função óbvia de professor, outras que antes os pais desempenhavam em relação aos filhos, isso tudo acrescido às de policial, psicólogo, burocrata, gerenciador de grupos e animador de auditório! Como é possível que alguém humanamente possa executar com eficácia e profissionalismo um enorme leque de tarefas acumuladas que outros profissionais acabam fazendo com perfeição justamente porque elas estão corretamente 
divididas e dosadas segundo a competência específica desses mesmos profissionais!

Não resta dúvida que essas circunstâncias massacrantes, aliadas a uma deficiência crônica de recursos materiais, resultem freqüentemente em quadros patológicos crônicos, físicos e psíquicos. Mas o envenenamento silencioso da função docente consiste mais exatamente na sensação de desamparo inexorável e de hostilidade dirigida a si mesmo e aos outros: sementes da renúncia à liberdade, ao crescimento pessoal, à responsabilidade. Que o Grande Irmão, ou Aquilo, cuide de tudo; só faço obedecer como um zumbi à Santa Vontade, ainda que outros sofram ou sejam excluídos da ética e da justiça.

E não é fácil ter a quem recorrer, diante de um conjunto de fatores que contribuem para o isolamento profissional do professor - uma semi-profissão tão carente de coesão interna que, para "existir", precisa ser legitimada pelo Outro. Pois, enquanto que, em profissões como a medicina, a psicologia, a odontologia, para falar de algumas, a voz que proclama e disciplina a competência vem "de dentro" — dos próprios profissionais credenciados, enfim, do próprio Sujeito -, na (semi-)profissão de professor, são os discursos alienígenas (por exemplo, da voz "em off" de um ator, na voz de um leigo "contente") que outorgam a legitimidade e a credibilidade do professor. Como se qualquer um estivesse em condições de ir "ajudar voluntariamente" a escola indo lá "alfabetizar"!

Fica parecendo que as séries iniciais precisam mesmo é de "amigos da escola". Se, mais tarde, digamos numa sexta série, como resultado, o adolescente não souber que uma sentença começa com inicial maiúscula e termina com ponto final, tudo bem (?!)

Compare: "Nenhuma criança fora da escola" e "Toda criança tem o direito a ler e escrever". Qual destas frases você adotaria?

Reza a cartilha: a gramatiquice nossa de cada aula nos dai hoje, e perdoa-nos por ter procurado aprimorar alguma coisa, tentado fugir aos ritos que purificam os alunos de sua cultura extra-oficial!

No lugar da transformação das consciências, da assimilação criativa de conhecimentos, o que encontramos? Rotinas-rituais que objetificam e sacralizam estereótipos culturais. Ou mais grave ainda: ficções culturais: descrições e explanações apresentadas como normas únicas, definitivas, diante das quais qualquer alternativa é um "desvio" a ser erradicado (entenda-se: é apagado o direito de outros discursos existirem e terem credibilidade, inclusive os portadores das formas de representação das culturas subalternas.

Em outras palavras: não é importante, a rigor, que o aluno assimile ou mesmo creia no que lhe é "dado" em aula; mas a conformidade aos rituais é indispensável. Porque executar um ritual (ou dele participar) constantemente leva à aceitação. E ao conformismo de todos os envolvidos no "culto" ao saber (note a expressão "todos"), dado que ritos de sacralização forjam uma falsa consciência: é prometida a salvação, mas a prática aponta para a sujeição; as ansiedades são 
aliviadas, mas não se toca nas causas delas.

Se não há lugar para a palavra do aluno, suas ansiedades e desejos, seus modelos de identificação, as práticas de sala de aula constituem uma farsa. 0 aluno então responde a isso com rituais de resistência: transgressões, atos de violência ou de insolência, reações de esquiva ou de inibição às atividades, atitudes de inversão carnavalesca (destronamento de autoridade).

E, finalmente, resta mencionar outro fator agravante do assim-chamado mal-estar docente (acabamos de dar o nome aos bois). Trata-se da forma como o assujeitamento funciona na sociedade pós-moderna. Há algumas décadas, o professor ainda tinha uma carta na manga: o período moderno estruturava (ainda) o desejo do aluno (e dos demais membros da sociedade) de acordo com a Lei, isto é, operava-se socialmente a castração, para empregar o jargão freudiano. Tornando as coisas mais claras: sobre o sujeito operava o Nome-do-Pai, isto é, a letra da Lei, que permitia a satisfação do desejo sob a condição de regulá-lo de acordo com as normas da vida social. O sujeito sujeitava-se à proibição (= isto e aquilo não pode; mas tudo que não é proibido é permitido) e isto o deixava livre para ajustar sua conduta de maneira pessoal, buscando realizar-se de quaisquer formas que não violassem os limites da Lei. A autoridade tinha, então, uma função clara e mais saudável: vigiava a "cerca" que não podia ser transpassada; dentro desta, valia a busca pessoal, ou seja, peregrinar em direção a um modelo socialmente valorizado de conduta tal que, se atingido, faria o sujeito digno de ser amado pelo Outro em função do que escolheu ser.

Mas na pós-modernidade a Lei é encarnada por uma Mãe Nutriz que exerce uma forma cruel de despotismo aparentemente benévolo: em princípio, não há "proibições", mas tenha tais e tais condutas, independentemente de quem você seja; porque, se não se enquadrar nos modelos prescritos, você será um desviante, pois não "reconhece" que esses comportamentos o farão gozar sem limites. Se não conseguir, precisa de "tratamento" - vale dizer, outros (especialistas, peritos, autoridades) o guiarão na sua incapacidade crônica. $O$ sujeito pós-moderno é aquele que é obrigado a gozar mas é incapaz de fazê-lo como "deveria". Deve sujeitar-se a um leque de prescrições, deixando ao Outro Anônimo a responsabilidade pela legitimidade das alegações "científicas".

Diante desse quadro, fica mesmo difícil ser o "guardião dos limites" do aluno; e, no entanto, este aparece testando constantemente esses limites ("Até onde o professor me deixa ir?", pergunta um aluno privado da castração que, inconscientemente, repudia mas ao mesmo tempo anseia: só a Lei, ou o Nomedo-Pai, pode emancipar; ainda que, ressaltemos, seja a Lei de seu segmento social, dos valores, atitudes e práticas adotados por este último - pois a homogeneidade sócio-cultural não existe).

Assistimos, hoje, perplexos, à morte do desejo do aluno. Onde está a motivação, a identificação com algum Ideal, a vontade de ser-mais? Ou, se quisermos: onde está o esforço de alunos, famílias e sociedade (leia-se: opinião pública) para unir o desejo à Lei? Das duas, uma: com a conivência ou omissão de pais e outros adultos, ou o professor precisa lidar com uma criança massacrada, um "burro por 
encomenda", um predestinado à exclusão; ou, com um "reizinho do mundo" — aquele que, para reinar, pode até (os pais até dão uma forcinha...) passar por cima de professores ou outras figuras da instituição escolar com um rolo compressor!

Diante de tudo que discutimos, o que se depreende, e o que fazer?

Vamos por partes, que o assunto é complexo. Quanto à manutenção perversa de rituais escolares vazios destinados a domesticar e não ensinar; à situação de semi-profissionalização crônica do educador; ao isolamento profissional e às dificuldades para se reciclar e se revitalizar; e, finalmente, à legitimação vinda de fora, penso que o caminho seja acionar mecanismos político-jurídicos para profissionalizar a categoria. Sabemos bem os avanços implicados na regulamentação das profissões, na criação de Conselhos regionais e federais, na influência destes sobre formação de profissionais da categoria, condições de exercício profissional, políticas de remuneração, etc.

Para quem me responda: mas há múltiplas áreas do conhecimento envolvidas! Sim, sem dúvida que há. Mas veja bem: uma, falo da profissionalização do educador; e outra, para sub-áreas, podemos dispor de associações nacionais. Dessa forma, o professor como profissional tem melhores condições para resgatar a auto-estima, os benefícios de um saudável corporativismo, o respeito dos demais segmentos da sociedade. Será menos penoso falar com alunos e pais de alunos, discutir problemas mais sérios com eles, se considerarem que diante deles há um sujeito-portador-de-saber. E de competência, até prova em contrário.

O(a) leitor(a) estará também perguntando: e esse acúmulo de funções, esse "desdobrar-se" para resolver de tudo na escola até que chegue o colapso nervoso ou outro motivo para uma aposentadoria precoce? Aqui faço duas considerações. A primeira delas: assim como temos, em outras profissões como medicina ou direito, a setorização das competências (= especializações), o mesmo pode perfeitamente ocorrer na educação (o que tem sido até agora flutuante e precário). Por exemplo, é possível pensar - meu exemplo agora é das Letras - num professor "formador", que cuide das competências para ler, escrever, aprender, refletir; ou num professor "preparador", como o que trabalha em pré-vestibulares ou pré-concursos; ou ainda num professor "designer", que cria, pilota e aperfeiçoa cursos e/ou materiais didáticos. Objetivos diferentes, funções diferentes, competências diferentes. Sem "acúmulo". E podem (mais do que isso, devem !) trabalhar integradamente - a investigação-ação educacional o permite muito bem. Hoje as cabeças trabalham em rede (alguém duvidaria?).

A segunda: numa escola com as mazelas que hoje encontramos - vou focalizar agora especificamente o ensino de língua materna, principalmente no ensino médio - o professor fica perplexo diante do nó górdio representado pela necessidade simultânea de "preparar" alunos para a seleção ao $3^{\circ}$ grau e tratar das seqüelas que ficaram de anos pregressos de mau ensino (como a incapacidade de construir um parágrafo coeso e coerente, digamos). É uma tarefa hercúlea, humanamente impossível aos pobres mortais! Então ele se omite e "dá gramática". Mas, para saber onde reside a solução, retrocedamos às séries 
iniciais.

O período de alfabetização e pós-alfabetização é o que mais tem sido maltratado. Os problemas daí decorrentes passam a ser, então, empurrados à frente: que o próximo professor dê um jeito nisso! Se as séries iniciais (e as posteriores) fossem verdadeiramente devotadas ao trabalho sério e responsável de ensinar e consolidar as competências de leitura e escrita, teríamos, até cerca do final do ensino básico ( $8^{\mathrm{a}}$ série), alunos capazes de executar tarefas dominando as habilidades comunicativas em nível supra-intermediário, quase avançado. Nessas condições, as aulas do ensino médio poderiam perfeitamente ser devotadas em boa parte para o ensino da metalinguagem gramatical (regras e formas, relações entre regras, relações entre formas), que por sua vez cumpriria a função de fazer o aluno "passar no vestibular", além de facilitar o aperfeiçoamento de alguns aspectos do processo de leitura e escrita em nível avançado. Se as funções de formador e preparador hoje se acumulam, é porque, desde as primeiras vezes em que o aluno ocupa um banco de escola, ele defronta-se com um "ensino" em estado desesperador. Invista-se na seriedade e competência do trabalho pedagógico nas séries iniciais, e não será preciso fazer professores do ensino médio tirarem leite das pedras.

$\mathrm{E}$ até que essas condições que tanto queremos sejam atingidas? Bem, poderão sê-lo na medida em que houver uma vontade política operante; e você, caro(a) amigo(a), potencialmente faz parte dela. E, como mostra a psicanálise, o que você pretende fazer do/com o seu desejo é responsabilidade sua.

Fecho com uma citação que já apareceu, preambular, n'O Medo à Liberdade, de Erich Fromm:

Se eu não for por mim mesmo, quem será por mim? Se eu for apenas por mim, que serei eu? Se não agora - quando?

\section{BIBLIOGRAFIA}

De LAJONQUIÈRE, LEANDRO. De Piaget a Freud: para repensar as aprendizagens. Petrópolis: Vozes, 1996. De LAJONQUIÈRE, LEANDRO. Infância e ilusão (psico)pedagógica. Petrópolis: Vozes, 1999.

FROMM, ERICH. O medo à liberdade. Rio de Janeiro: Zahar, 1972.

McLAREN, PETER. Rituais na escola. Petrópolis: Vozes, 1991.

RICHTER, MARCOS GUSTAVO. "Salvai-os porque eles sabem o que fazem Ou da consciência cínica à autonomia no cotidiano escolar". In: Linguagem \& Ensino. Vol. 2, № 1, Jan 1999. 


"

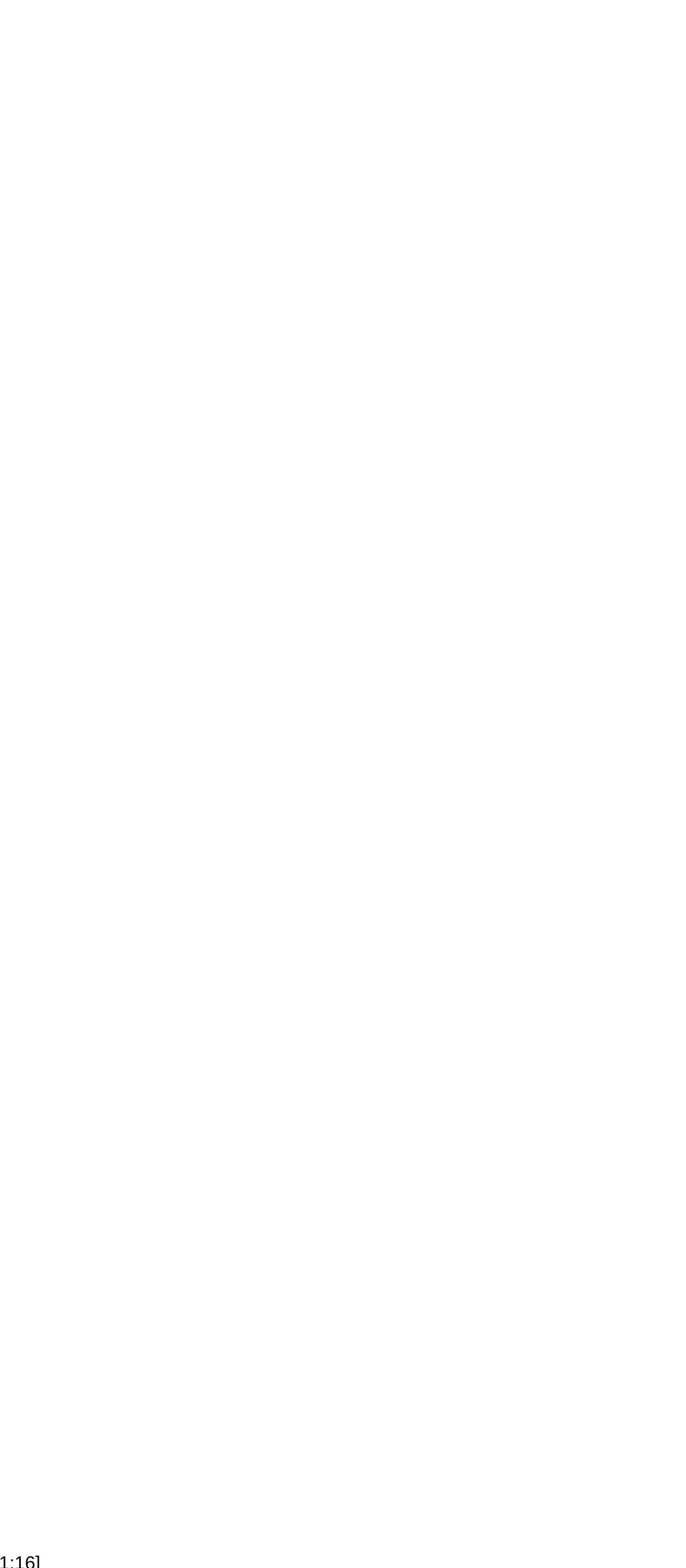

